\title{
GROWTH AND YIELD OF Pleurotus ostreatus MUSHROOM ON DIFFERENT LIGNOCELLULOSIC WASTES \\ El-Sawah, M.M.A. ${ }^{1}$; M.M.Kassem ${ }^{1}$ and Rasha Y.Y. El-Nafad ${ }^{2}$ \\ ${ }^{1}$ Microbiol. Dept., Fac. Agric., Mansoura Univ., Mansoura, Egypt. \\ ${ }^{2}$ Food Technol. Instit., Agric. Res. Center (ARC), Giza, Egypt.
}

\begin{abstract}
Five strains of oyster mushroom, Pleurotus ostreatus (Jacq. ex. fr) Kummer, differing in mycelium extension rate and colony morphology were cultivated on synthetic media and sterile rice straw. Under these conditions, growth rate and loss of organic mass were investigated. The strain $P$. ostreatus PO 3 showed high ability to decompose the lignocellulosic substrate, rice straw, and a relatively high loss of organic mass was found after 60 days of cultivation of this strain. Evaluation of some lignocellulosic wastes, as substrates for cultivation of the $P$. ostreatus, revealed that the density of the mycelium was comparatively rich, uniform and white on rice straw. The mycelium of the fungus totally colonized the wastes within a period of 30 days of spawn run. The yields of mushroom on the different substrates were $625.30,651.17,622.17,600.18,597.83,448.52,250.75$ and $450.75 \mathrm{~g} / \mathrm{kg}$ dry weights of wheat straw, rice straw, barley straw, corn stalks, banana leaves, sugar cane bagasse, saw dust and water hyacinth, respectively. The biological efficiency followed the same pattern and ranged from $25.12 \%$ for sawdust to $65.15 \%$ for rice straw. The yield of fungus was positively correlated to cellulose $(r 2=0.129)$, lignin $(r 2=0.991)$ and crude fibre $(r 2=0.174)$ contents of the wastes. Based on the yield and biological efficiency of the wastes tested, rice straw recommended to be the best waste for Oyster cultivation.

Key words: degradation, Pleurotus ostreatus mushroom, lignocellulosic wastes, yield, rice straw, biological efficiency.
\end{abstract}

\section{INTRODUCTION}

Oyster mushrooms (Pleurotus species) are the second largest commercially produced mushroom in the world. It represents $25 \%$ of total world production of cultivated mushrooms. Pleurotus mushrooms are cultivated world-wide for food and China is the major producer. In the wild they are usually found growing on wood (Phillips, 2006). The dramatically increase in recent years in growing and consumption of oyster mushroom is largely due to its taste, medicinal and nutritional properties (Garcha et al., 1993).

$P$. ostreatus, one of the most-produced species, is cultivated mainly on agricultural lignocellulosic wastes. In Egypt, huge amounts of lignocellulosic wastes can be found. Some of these wastes are left to rot in the field or are disposed off through burning process. Cultivation of mushrooms on these wastes may be one of the solutions to transforming these wastes into accepted edible biomass of high market value. The spent substrates from mushroom cultivation on wastes can also potentially be used as an animal feed supplement, possibly providing additional animal feed resources (Gregori et al., 2007). Pleurotus species, a widely accepted mushroom cultivated in Egypt, degrades and grows directly on these lignocellulosic wastes (Gregori et al., 2007). Although, large volumes of wastes are available in Egypt, their use as substrate for mushroom cultivation has not been fully exploited.

This paper reports on the comparative utilization of some lignocellulosic wastes as substrates on the growth rate and yield of $P$. ostreatus using the plastic bag method (Oei, 1991). This method is more reliable, in that it produces better and more stable yields, than the traditional commercial methods of cultivation.

\section{MATERIALS AND METHODS}

\section{Organisms}

Pleurotus ostreatus (Jacq. ex. fr) Kummer strains were maintained on malt extract agar slants and spawn was prepared on sorghum grains (Zadrazil, 1978).

\section{Mycelium extension rate on Petri dishes}

This was estimated by measuring the diameters of four individual colonies grown separately on the solid agar medium ( $\mathrm{pH}$ 5.5), (Kirk et al., 1978), in Petri dishes inoculated with agar plugs (1-mm diameter) cut with an injection needle from the actively growing part of colony on another Petri dish. All measurements were repeated three times and done in quadruplicate. 


\section{Growth rate in sterile straw}

Glass tubes (inner diameter $30 \mathrm{~mm}$ ) were filled with $25 \mathrm{~g}$ of air-dried milled rice straw (particle size $<1 \mathrm{~mm}$ ), forming a $60-\mathrm{mm}$ column, then supplemented with $2 \mathrm{ml}$ of water and sterilized by autoclaving (45 minutes at $121^{\circ} \mathrm{C}$ ). The tubes were then inoculated with a $10-\mathrm{mm}$ agar plug cut from the actively growing part of the mycelial colony. The cultivations proceeded in $25^{\circ} \mathrm{C}$. During the cultivation, the fungal growth was assessed daily by measuring the visible penetration of mycelia into the straw (Lang et al., 1997). After 14 days of growth the colonization ability of each strain was expressed as the percentage of the height of the colonized straw column in proportion to the total height of the straw column. Three replicates were used for each treatment.

\section{The loss of organic mass}

Erlenmeyer flasks $(500 \mathrm{ml})$ containing $25 \mathrm{~g}$ of air dried milled rice straw (particle size $<1 \mathrm{~mm}$ ) were sterilized by autoclaving $\left(45\right.$ minute at $121^{\circ} \mathrm{C}$ ) and inoculated with two $10-\mathrm{mm}$ agar plugs cut from the actively growing part of the mycelial colony. The flasks were then incubated for 60 days at $25^{\circ} \mathrm{C}$. At the end of the cultivation, the content of each flask was dried at $100^{\circ} \mathrm{C}$ until the constant weight, weighed and the loss of organic mass was determined. The dry mass of sterile straw cultivated under the same conditions without fungus was used as a control. Three replicates were used for each strain and treatment. Growing

Wheat straw, rice straw, barley straw, corn stalks, banana leaves, sugar cane bagasse, saw dust and water hyacinth were chopped into $\sim 5 \mathrm{~cm}$ lengths parts and soaked in water overnight in basins. Excess water was drained and the substrates dried in the sun for $2 \mathrm{~h}$. The substrates were also thoroughly mixed with $5 \%$ wheat bran and $5 \%$ of calcium sulfate and bagged in heat-resistant polypropylene bags. Each bag was closed with a plastic neck, steam-sterilized for $2.5 \mathrm{~h}$ and inoculated with $4 \%$ sorghum spawn (the substrates were subjected to these different treatments to ensure maximum yields). The bags were then incubated at $25^{\circ} \mathrm{C}$ and $60-65 \% \mathrm{RH}$ for $\sim 3$ weeks in a well-ventilated, semi-dark room. The mean radial growth per week and the spawn run period to total colonization (i.e., the number of days from inoculation to complete colonization of the compost bag by the mycelium) were recorded.

\section{Cropping}

After completion of the spawn run, the bags were transferred onto horizontal racks in a cropping room-a wooden-frame structure covered with woven mats. The bags were then opened and the mats were watered twice a day to increase the humidity and induce fruit body formation. The interior of the house reached $25^{\circ} \mathrm{C}$ and $90-95 \% \mathrm{RH}$. Time was recorded in days for the completion of growth of mycelium on substrates, appearance of pinheads, maturation of fruiting bodies in different treatments. The data were also recorded for the yield number of fruiting bodies and biological efficiency of substrates. The total biological efficiency was worked out against the dry weight of each substrate.

The number of days until the first appearance of the mushroom was recorded. The biological efficiency,

i.e. the weight of fresh mushrooms as a percentage of the dry weight of the substrate was determined.

\section{Chemical analysis}

The experiment was replicated five times for each by-product substrate.

Analyses were carried out on the wastes on which the mycelium grew. The wastes were powdered and analysed for various constituents: cellulose, hemicellulose, lignin, fibre and, crude protein and ash (AOAC, 1990).

Moisture content was determined by drying $5 \mathrm{~g}$ of each substrate at $107^{\circ} \mathrm{C}$ overnight. Acidity $(\mathrm{pH})$ was measured using an Alpha 500 model laboratory $\mathrm{pH} / \mathrm{mV}$ meter.

\section{Statistical analysis}

For each analysis, there were four replicates. Data were submitted to a one-way analysis of variance. The total yield of mushroom per waste was separated by Duncan's multiple range tests at $a=0.05$. Correlation analyses were carried out in order to determine the relation of each chemical constituent with the total yield of mushroom pooled from all the substrates. All statistical analyses were performed using SPSS 10 for Windows (SPSS, 1999).

\section{RESULTS AND DISCUSSION}

\section{Growth rate on artificial media}

As a criterion for the growth of Oyster strains on solid media, mycelium, an extension rate was used. The tested strains of $P$. ostreatus showed remarkable changes in their growth rates, determined as a mycelium extension rates on complete GC 3\% agar medium,. The growth rate ranged from 4.47 to 10.10 
$\mathrm{mm} /$ day. The higher growth rate was recorded for $P$. ostreatus strain PO 3 (Table 1). The results are in line with Eichlerov'a et al. (2000).

\section{Colonization of sterile rice straw}

The results of straw colonization experiments are also presented in Table 1. Most of the tested strains colonized the rice straw with slow rate at $25^{\circ} \mathrm{C}$. P. ostreatus strain 3 exhibited the higher growth rate. The results indicate a positive correlation between the growth rate tested on GC $3 \%$ agar medium and on the natural substrate, i.e., rice straw. A higher growth rate on the agar plates corresponded to a higher ability to colonize straw and the strains with the low growth rate on medium also grew slowly on rice straw. Among the different lignocellulosic wastes tested as substrates for the cultivation of P. ostreatus, rice straw were found to best support growth of the fungus, with the mycelium fully colonizing the substrates at 18.23 days (Table 2).

\section{Degradation of sterile rice straw}

The majority of $P$. ostreatus strains caused a higher loss of organic mass during cultivation at $25^{\circ} \mathrm{C}$ (Table 1). The degradation of rice straw reached $32.20 \%$ within 60 days. Zadrazil (1985) similarly tested 235 different strains and also found the higher loss of organic mass mostly at $30^{\circ} \mathrm{C}$. No more than $23.3 \%$ of straw dry weight was degraded by any $P$. ostreatus strain within 60 days. A strong correlation was found between the growth rates of the strains in straw columns and the degradation of straw. Eichlerov'a et al. (2000) found that some $P$. ostreatus isolates showed a very good ability to decompose the lignocellulosic substrate, straw, and a relatively high loss of organic mass was found after 50 days of cultivation in these strains.

Table 1: Characterization of $P$. ostreatus strains undercultivation on synthetic media and sterile rice straw.

*after 60 days of cultivation.

\begin{tabular}{|l|c|c|c|}
\hline \multirow{2}{*}{ Strains } & \multicolumn{2}{|c|}{ Growth rate at $\mathbf{2 5}^{\circ} \mathbf{C}(\mathbf{m m} /$ day $)$} & $\begin{array}{c}\text { Loss of organic } \\
\text { mass\% }\end{array}$ \\
\cline { 2 - 3 } & Petri dishes & Sterile straw & 13.78 \\
\hline P. ostreatus strain PO 1 & 5.72 & 0.95 & 16.07 \\
\hline P. ostreatus strain PO 2 & 4.47 & 0.89 & 32.20 \\
\hline P. ostreatus strain PO 3 & 10.10 & 3.95 & 22.20 \\
\hline P. ostreatus strain PO 4 & 6.15 & 0.98 & 29.18 \\
\hline P. ostreatus strain PO 5 & 8.20 & 1.10 & \\
\hline
\end{tabular}

\section{Mycelial growth on various wastes}

The density of the mycelium was comparatively poor on sawdust and sugar cane bagasse (Table 2). The mycelium density was uniform, white, very thick and dense in the other six substrates, namely wheat straw, rice straw, barley straw, corn stalks, banana leaves and water hyacinth. The mycelium of the fungus totally colonised the saw dust within a period of 25 days of spawn run. The highest mean radial growth of the mycelium was recorded on rice straw, followed by wheat straw and barley straw. Pleurotus spp. are reported to be efficient colonizers and degraders of lignocelluloses (Poppe, 2000).

Table 2: Weakly mycelial growth at $25^{\circ} \mathrm{C}$ of $P$. ostreatus strain $\mathrm{PO} 3$ on various wastes.

\begin{tabular}{|l|c|c|c|}
\hline Wastes & $\begin{array}{c}\text { Surface mycelial } \\
\text { density }^{*}\end{array}$ & $\begin{array}{c}\text { Total colonization } \\
\text { period (days) }\end{array}$ & $\begin{array}{c}\text { Diameter (cm) of } \\
\text { mycelial growth/week }\end{array}$ \\
\hline Wheat straw & +++ & 16.22 & \\
\hline
\end{tabular}

\begin{tabular}{|l|c|c|c|}
\hline \multicolumn{1}{|c|}{18.23} & 5.0 & \\
\hline Barley straw & +++ & 17.25 & 4.8 \\
\hline Corn stalks & ++ & 18.00 & 4.0 \\
\hline Banana leaves & & & \\
\hline \multicolumn{2}{|c|}{19.01} & \\
\hline
\end{tabular}

Sugar cane bagasse+24.504.0Saw dust+25.004.0Water hyacinth++21.184.0*Degree of mycelial density when the mycelia

fully colonises the substrate: + poor running growth, ++ mycelium grows throughout the whole bag but is not uniformly white,+++ mycelium grows throughout the whole bag and is uniformly white.

\section{Primordia and fruiting bodies}

The primordia started appearing 4-6 days after the bags had been transferred to the cropping room and opened (Table 3). This varied from substrate to substrate. Wheat straw gave the fastest mycelial 
growth rate; however, this did not correspond with yield, indicating that mycelial growth and yield of mushrooms have different requirements (Oei, 1991).

Table 3: Days for formation of primordia and fruiting bodies of $P$. ostreatus strain $\mathrm{PO} 3$ at $25^{\circ} \mathrm{C}$ on various wastes.

Number/kg substrate dry weight.

\begin{tabular}{|l|c|c|c|}
\hline \multicolumn{1}{|c|}{ Wastes } & $\begin{array}{c}\text { Primordia } \\
\text { formation (days) }\end{array}$ & $\begin{array}{c}\text { Fruiting bodies } \\
\text { formation (days) }\end{array}$ & $\begin{array}{c}\text { Average number } \\
\text { of fruiting bodies }\end{array}$ \\
\hline Wheat straw & 21.15 & 25.25 & 22.66 \\
\hline Rice straw & 22.50 & 26.15 & 25.23 \\
\hline Barley straw & 23.22 & 26.18 & 21.24 \\
\hline Corn stalks & 23.15 & 27.12 & 21.88 \\
\hline Banana leaves & 24.12 & 26.90 & 23.27 \\
\hline Sugar cane bagasse & 29.25 & 32.90 & 18.28 \\
\hline Saw dust & 31.32 & 35.21 & 16.70 \\
\hline Water hyacinth & 26.00 & 30.00 & 19.67 \\
\hline
\end{tabular}

\section{Yield and biological efficiency}

Data on the quantity of sporophores harvested in different flushes are presented in Table 4. Tested agricultural wastes recorded various flushes. The first flush of crop gave $50 \%$ of the yield obtained in all the by-product substrates tested. During the 8 weeks of cropping, the highest total weight of mushrooms harvested on $1 \mathrm{~kg}$ substrate was recorded on rice straw. This was followed by wheat straw with a total weight of $651.17 \mathrm{~g}$. Analysis of mushroom yield revealed significant differences $(P<0.05)$ between substrates. Rice straw were superior to all the other substrates.

Biological efficiency of $P$. ostreatus strain PO 3 production varied in different used substrates (Table 4). The maximum biological efficiency of $52.0 \%$ was recorded with rice straw followed by wheat straw, at $50.98 \%$. Evaluation the use of lignocellulosic biomass from coconut palm as substrate for cultivation of $P$. sajor-caju, Thomas et al. (1998) reported that the yield of $P$. sajor-caju is directly related to the spread of the mycelium into the substrate. Abodai et al. (2003) found that the quantity of mushrooms harvested was significantly $(P<0.05)$ greater in composted sawdust than in any of the other substrates. The superiority of the two substrates was also evidenced in their biological efficiency, with composted sawdust showing $61.04 \%$, and rice straw $50.64 \%$. Variable ranges of biological efficiency have been reported when different lignocellulosic by-products were used as substrates. When $P$. ostreatus was grown on fermented coffee pulp, a biological efficiency value of $132 \%$ was obtained, while $37.7 \%$ was recorded on $P$. sajor-caju grown on leaf sheath of arecanut palm.

Table 4: Yields of $P$. ostreatus strain $\mathrm{PO} 3$ at $25^{\circ} \mathrm{C}$ and biological efficiency on various wastes.

\begin{tabular}{|l|c|c|}
\hline \multicolumn{1}{|c|}{ Wastes } & $\begin{array}{c}\text { Total fresh weight of fungus } \\
\text { g/kg substrate dry weight }\end{array}$ & $\begin{array}{c}\text { Biological } \\
\text { efficiency (\%) }\end{array}$ \\
\cline { 2 - 4 } Wheat straw & $625.30 \pm 3.2^{\mathrm{b}}$ & 62.53 \\
\hline Rice straw & $651.17 \pm 0.7^{\mathrm{a}}$ & 65.15 \\
\hline Barley straw & $622.17 \pm 1.7^{\mathrm{c}}$ & 62.26 \\
\hline Corn stalks & $600.18 \pm 0.5^{\mathrm{d}}$ & 60.02 \\
\hline Banana leaves & $597.83 \pm 2.0^{\mathrm{d}}$ & 59.80 \\
\hline Sugar cane bagasse & $448.52 \pm 3.1^{\mathrm{e}}$ & 44.93 \\
\hline Saw dust & $250.75 \pm 0.8^{\mathrm{f}}$ & 25.12 \\
\hline Water hyacinth & $450.75 \pm 3.4^{\mathrm{e}}$ & 45.10 \\
\hline
\end{tabular}

g kg substrate dry weight.

\section{Mushroom yield and wastes}

Data on the chemical composition of the by-products tested for $P$. ostreatus strain PO 3 production are presented in Table 5. The by-products differed significantly $(\mathrm{P}<0.05)$ in the concentration of constituents such as lignin, cellulose, and nitrogen. Sawdust had higher cellulose and lignin contents compared to the other by-products while banana leaves had the highest nitrogen content of all the by-products tested.

Correlation studies between the constituents of the substrates and mushroom yield (Table 6) revealed non significant positive relationship with cellulose content $\left(\mathrm{r}_{2}=0.129\right)$ and crude fiber content $(\mathrm{r} 2=0.174)$. Substrates and 
mushroom yield revealed significant positive relationship with lignin content $(\mathrm{r} 2=0.991)$. However, sporophore production was negatively related to hemicellulose $\left(\mathrm{r}_{2}=0.917\right)$.

The positive relationship obtained in the present study between mushroom yield and cellulose ( $r 2$ $=0.129)$ and lignin $(r 2=0.991)$ and crude fibre $(r 2=0.174)$ contents revealed that these components are an important factor for fruit body formation. Cellulose-rich organic materials were reported to be good substrates for the cultivation of mushrooms. Experiments carried out by Xiujin et al. (2000), revealed that during fruit body formation of $P$. ostreatus on cotton seed hulls there is a significant decrease in cellulose content after the flushing of mushrooms, indicating that more cellulose is used during fruiting. This does not compare favourably with the results of Zhanzi and Zhanhua (1997) who recorded high yields of mushroom. Further treatments, such as composting the substrates for varying periods, can improve yield.

Table 5: Composition of lignocellulosic wastes used as substrate for $P$. ostreatus strain PO 3 cultivation.

\begin{tabular}{|l|c|c|c|c|}
\hline \multicolumn{1}{|c|}{ Wastes } & Wheat straw & Rice straw & Barley straw & Corn stalks \\
\hline Cellulose & 39.32 & 41.20 & 40.09 & 39.43 \\
\hline Hemicellulose & 26.07 & 25.14 & 28.10 & 32.13 \\
\hline Lignin & 9.07 & 10.23 & 9.20 & 8.05 \\
\hline Crude fibre & 34.97 & 30.00 & 35.10 & 28.00 \\
\hline Nitrogen & 0.90 & 0.85 & 0.88 & 0.82 \\
\hline Ash & 9.90 & 16.12 & 9.00 & 5.8 \\
\hline Moisture & 61.20 & 65.98 & 62.00 & 61.22 \\
\hline pH of medium & 7.50 & 7.40 & 7.50 & 7.20 \\
\hline
\end{tabular}

Table 6: Correlation between $P$. ostreatus strain PO 3 yield and constituents of lignocellulosic wastes.

\begin{tabular}{|l|c|}
\hline \multicolumn{1}{|c|}{ Constituents } & Yield \\
\hline Cellulose & 0.129 \\
\hline Hemicellulose & $-0.917^{*}$ \\
\hline Lignin & $0.991^{\star *}$ \\
\hline Crude fibre & 0.174 \\
\hline
\end{tabular}

The selection of substrate for cultivation of mushroom is largely determined by the abundance and cost of the substrate. The most widely used substrate for the cultivation of oyster mushroom in Egypt is rice straw, but its shortage or unavailability in some areas makes it imperative to find alternative sources. Thus, rice straw, which gave relatively good yields, could be an alternative substrate for mushroom cultivation in rice-growing areas.

\section{REFERENCES}

AOAC (1990). Official methods of analysis. Association of Official Analytical Chemists. Washington, D.C.

Eichlerov'a, I., L. Homolka, F. Nerud, F. Zadrazil, P. Baldrian and J. Gabriel (2000). Screening of Pleurotus ostreatus isolates for their ligninolytic properties during cultivation on natural substrates. Biodegradation 11: 279-287.

Garcha, H.S., P.K. Khanna and G.L. Soni (1993). Nutritional importance of mushrooms. In: Chang, S.T., Buswell J.A., Chiu S (eds.) Mushroom biology and mushroom products. Chinese University Press, Hong Kong.

Gregori, A., M. Svagelj and J. Pohleven (2007). Cultivation Techniques and Medicinal Properties of Pleurotus spp., Food Technol. Biotechnol. 45 (3) 238-249.

Gregori, A., M. Svagelj and J. Pohleven (2007). Cultivation techniques and medicinal properties of Pleurotus spp. Food Technol. Biotechnol. 45(3) 238-249.

Kirk, T.K., E. Schultz, W.J. Connors, L.F. Lorenz and J.G. Zeikus (1978). Influence of culture parameters on lignin metabolism by Phanerochaete chrysosporium. Appl. Microbiol. 117: 277-285.

Lang, E., G. Eller and F. Zadrazil (1997). Lignocellulose decomposition and production of ligninolytic enzymes during interaction of white-rot fungi with soil microorganisms. Microb. Ecol. 34: 1-10.

Obodai, M., J. Cleland-Okine and K.A. Vowotor (2003). Comparative study on the growth and yield of Pleurotus ostreatus mushroom on different lignocellulosic by-products. J. Ind. Microbiol. Biotechnol. 30:146-149. 
Oei, P (1991). Manual on mushroom cultivation: techniques, species and opportunities for commercial application in developing countries. CTA, Wageningen, The Netherlands.

Phillips, R. (2006). Mushrooms. Pub. McMilan, ISBN 0-330-44237-6. P. 266.

Poppe, J (2000). Use of agricultural waste materials in the cultivation of mushrooms. Mushroom Sci. 15:323.

SPSS (1999) SPSS 10 for Windows. SPSS, Chicago, III.

Thomas, G.V., S.R. Prabhu, M.Z. Reeny and B.M. Bopaiah (1998). Evaluation of lignocellulosic biomass from coconut palm as substrate for cultivation of Pleurotus sajor-caju (Fr.) Singer. World J. Microbiol. Biotechnol. 14:879-882.

Xiujin L, Yunzhi $P$, Zhang R (2000) Compositional changes of cottonseed hull substrate during $P$. ostreatus growth and the effects on the feeding value of the spent substrate. Bioresour. Technol. 80:157-161.

Zadrazil F (1978) Cultivation of Pleurotus spp. In: Chang ST, Hayes WA (eds) The biology and cultivation of edible mushrooms. Chinese Univ. Press, Hong Kong.

Zadrazil F (1985) Screening of fungi for lignin decomposition and conversion of straw into feed. Angew. Botanik 59: 433-452.

Zhanzi L, Zhanhua L (1997). Jun-Cao technology. $2^{\text {nd }}$ Ed.. pp 70-71.

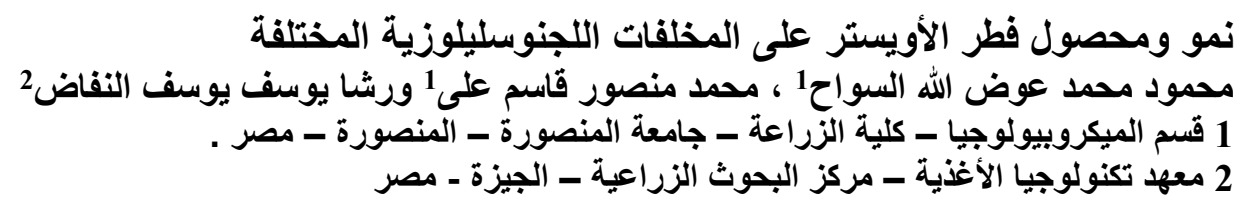

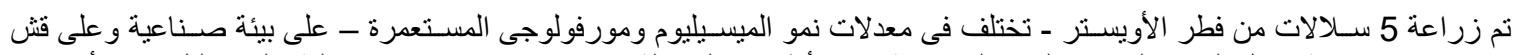

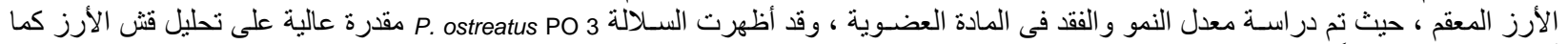

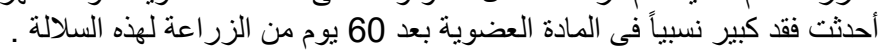

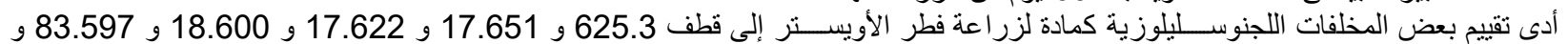

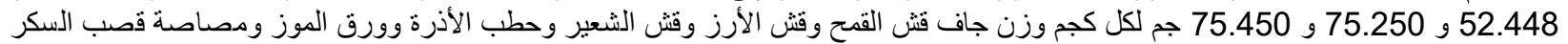

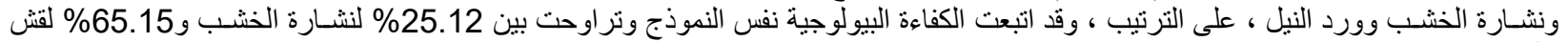

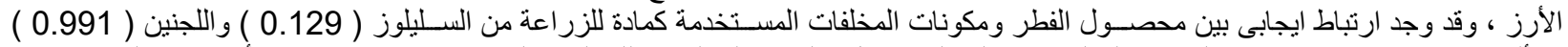

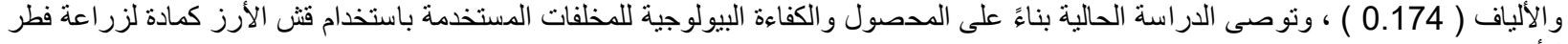
الأويستر . 